\title{
The Study on the Residential Space in Culture-led Urban Regeneration: a case study of Residential Space in Henan
}

\author{
Fan, Dan-Dan ${ }^{1, *}$, Kim, Se-Hwa ${ }^{2}$ \\ ${ }^{1}$ Department of Design, Dongseo University Graduate School, Korea \\ 2 Department of Design, Dongseo University Graduate School, Korea
}

\begin{abstract}
The concept of culture-led urban regeneration is one design solution for restoring urban vitality and re-creating urban culture based on the tangible and intangible cultural resources of the city. As an important part of culture, residential culture is changing with the development of society. Literature shows that there are still deficiencies in the study of residential culture in culture-led urban regeneration. This study tried to find the cultural identity and belonging in the residential space in one hand, create a suitable space layout in the other hand. The living space pattern of traditional and modern is summarized. The cultural characteristics of Henan province have been abstract and offering the basis of the improvement solution for living space from the perspective of cultural. This study offered the reference to the culture-led urban regeneration of Henan province.
\end{abstract}

\section{Introduction}

Urban regeneration is a strategic which aims to add new functions in physics, environment and culture of city in order to change the decline of urban appearance, and to re-activate the urban vitality after World War II. Urban regeneration methods include urban infrastructure such as roads and parks, building renovation, construction of industrial parks, preservation and restoration of historical landscape. Peter Robert agreed that urban regeneration is the planning and action to solve various problems of cities. It is a strategic approach to seek continuous improvement of economic, social and environmental conditions in regenerative areas [1].

Along with the rapidly developed economy of China since the Economic Construction, the concentration of cities and the functional modern architecture theory of Le Corbusier has brought the prosperity of cities. The technological progress dominated by economic development blurred cultural identity of cities. People could barely find sense of belonging from standardized modern buildings. Therefore, the focus of urban regeneration is expanded to the human value, historical significance and expression of cultural tradition other than physical environment.

As one of the cradles of ancient Chinese civilization, Henan is a historical province where has a high population density. The local cultural features were almost replaced by the unified modern architecture. However, architecture is not only the space as a shelter. When the basic needs are met, people need a higher level of spiritual needs and psychological satisfaction. How to build cultural confidence in living space, meet spiritual needs and reflect the development of cities with historical and cultural characteristics became necessary.

\section{Analysis of urban residential culture}

\subsection{Renewal of cultural urban}

The renewal of cultural city mainly includes four aspects: 1) re-generation of cultural resources (cultural heritage, natural resources, architecture, artwork); 2) composition of cultural space (museums, galleries, performing grounds, libraries), 3) cultivation of cultural industries (handicraft, tourism, top industries); and 4) community participation scheme (education, experience, competition, public activity) [2]. (Fig.1) The four aspect can be used alone or combined with each other. The cultivation of cultural industries such as tourism, the composition of cultural spaces such as museums and art galleries, and the transformation of old industrial areas are common strategies for the regeneration of culture-led urban generation. And culture should be embodied in spiritual values and lifestyles of people [3]. How to preserve culture and apply it to modern living space, so that people who live in it could find a sense of spiritual belonging has become an important aspect of cultural urban renewal research.

\footnotetext{
*Corresponding author: 492833921@qq.com
} 


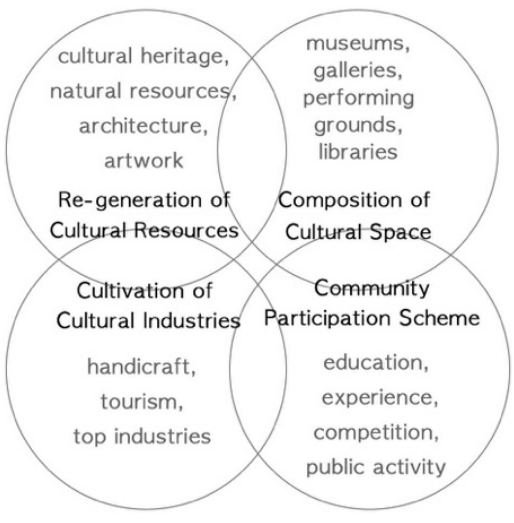

Fig. 1. Culture-led Urban Regeneration methods

\subsection{Case study of residential space in henan}

\subsubsection{Traditional urban residential form}

Henan is located in the Central China. The developed agriculture has promoted the development of rural settlements and the urban forms. The earliest urban planning ' $\mathrm{Lu} \mathrm{Li}$ ' appeared in the Xi Zhou dynasty. The whole city was square, and the houses were arranged in the order of status and blood. The position closer to the imperial palace is where the people with higher class. In the Bei Wei dynasty, Luoyang city was divided by the checkerboard streets into squares, which was the original form of 'Li Fang system'. A wall is set around the square, and each square opens a door on the four sides, which gate was closes at night. By the late Tang dynasty, the walls were abandoned, square developed to the open space [4]. During the Bei Song dynasty, Kaifeng city broke the system of subdivision of the square. Shops were opened by the street, and 'street lane' became the main space of public activities and information dissemination. In the mid-1980s, community system was proposed and gradually developed, which was a transformation of the residential mode of rapid urban development.

\subsubsection{Characteristics of traditional residential space}

The overall layout of residential in Henan province is square shape. Most buildings are located in north and faced to south. From the perspective of residential form, mostly large families live together as an independent housing system, which is different with apartment or house type. The house in the middle of the yard is a public space or a space for guests. With the sitting room as reference, each sides of the sitting room were designed rooms. The whole structure of the building emphasized symmetrical coordination.

From the perspective of space layout, the residential spaces are designed according to Feng-shui and hierarchy. First, except for the royal palace and official buildings, most houses are laid out as shown in Figure 2, the gate of the courtyard is opened Because of the traditional hierarchy, middle means the noblest. Secondly, the gate of the yard and the door of the house cannot be directly faced. It is not only because of the consideration of privacy protection, but also in the traditional Chinese feng shui indicated that the two faced doors would bring direct air flow, which may damage healthy. Third, the layout of the room is designed in order: the elders live in the middle room, the younger lived in the side rooms, the women lived in the inside yard rooms, the visitors and the servants lived in the outer yard rooms [5].

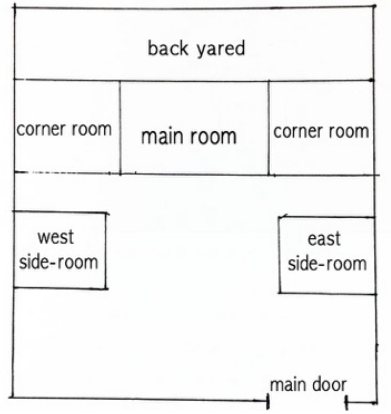

Fig. 2. Culture-led Urban Regeneration methods

From the perspective of climatic factors, Henan has distinctive seasons, with cold winter and hot summer. Ventilation and thermal insulation factors are important in residential design. The inward door in order to guide ventilation. The house is equipped with an eaves of about $60 \mathrm{~cm}$ width, which can withstand direct sunlight in summer and protect the wall from rain erosion.

From the perspective of the materials application, various of building materials were took from the natural environment. The cultural characteristics of using materials locally and adapt to local conditions are reflected from ancient cave dwellings to grass houses, cave houses, tile houses to buildings [6].

From the perspective of social distribution of labour, land is the dominant factor of social production. Agricultural activities require cooperation between families or neighbours. People were closely connected to each other. The connection brought the sense of belongings and safety.

Therefore, there are five characteristics of traditional residential culture in Henan from living form, space layout, climate, materials and social distribution of labour: 1) the traditional space layout of living space has diverse gradation, including Lifang, street lane, yard and residence, which was changed from open to private. 2) the room layout is distributed according to hierarchy and etiquette. 3) the protection of family privacy is important. 4) use the natural and local materials. 5. The gradual formation of public space promotes people's communication and social development.

\subsubsection{The change of modern residential space}

Modern urban residential space is mostly existing on the form of residential community. With the expansion of urban scale and the improvement of land utilization rate, the community of residential areas are gradually centralized. The modern residential spaces are changing by the rapid construction and promotion methods of constructors such as independent construction and closed management between the communities, the communities 
present two trends: the first trend is the unified layout and architectural combination, and the second trend is the borrowing exotic architectural style and characteristics. These residential spaces with two trends could barely reflect the local culture characteristics in perspective of visual or cultural inheritance. It may cause the resulting in the fracture and dislocation of urban culture and history. Moreover, those may affect people to form their cognition of urban cultural background or build the sense of belonging.

The residential area of modern urban shows the pattern of street, community and residence. However, the street and community is only way to enter the residence, people are more familiar with their homes. Communication between neighbours is rare. The traditional large-family living style is reduced; small family pattern becomes mainstream. Information technology and intelligent technology have become an indispensable part of people's life. People are immersed in scientific and technological information, they have less communication with the outside world, which resulting in less direct interpersonal communication.

There are good aspects in the construction of modern residential areas, such as the improvement of people's living conditions and the conservation and utilization of land. With the improvement of material conditions, people find the lack of spiritual culture in residence. Therefore, in order to combine the traditional living culture with the existing residential communities and create a more appropriate living space, we focus on analyzing the layout of living space.

\subsubsection{The layout of modern residential space}

In order to understand better of the structural layout in modern residential space, we analyzed the structural relations of space by using the methods of the Justified Graph in the Space Syntax of Bill Hillier [7]. Nodes are used to represent unit space and lines to represent the connection between spaces (Fig. 3).
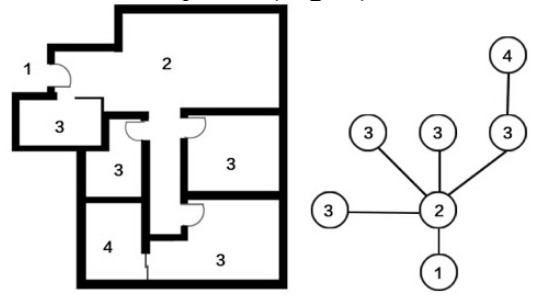

Fig. 3. Culture-led Urban Regeneration methods

1 is the part that connects the external and private realms, where is the channel space. 2 is the transition between different spaces, it connects to other spaces. The more the space is, the higher the openness and use frequency of the space are. 3 is a space that only be reached by passing through a certain area, with a certain privacy. 4 is the hidden space located in the deepest part, which is the last space to arrive.

$12100-162 \mathrm{~m}^{2}$ residential space distributed in four areas in Henan province were chosen and analyzed with 'Justified Graph' connection structure. Table 1)
Table 1. Residential space structure (J-graph).

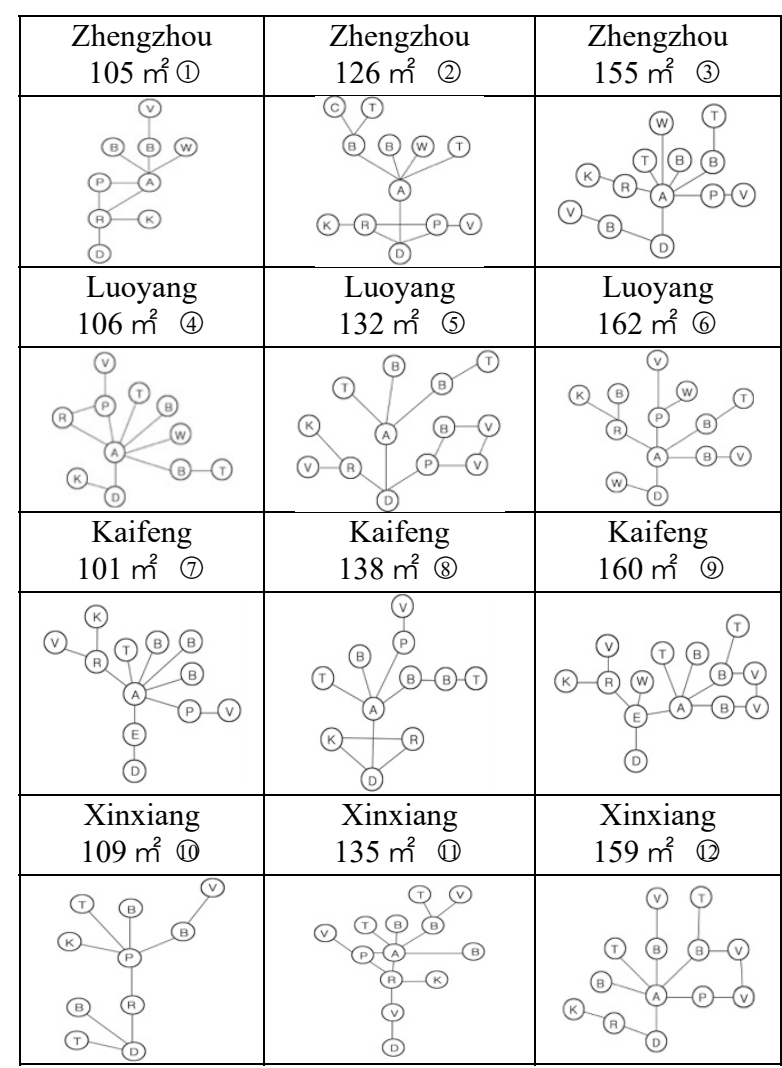

( $\mathrm{D}=$ Entrance $/ \mathrm{A}=$ Corridor $/ \mathrm{P}=$ Parlour $/ \mathrm{R}=$ Restaurant $/ \mathrm{K}=$ Kitchen $/$

$\mathrm{W}=$ Workroom $/ \mathrm{T}=$ Toilet $/ \mathrm{B}=$ Bedroom $/ \mathrm{V}=$ Balcony $/ \mathrm{E}=$ porch)

The spatial layout of the living room, dining room and corridor in the four spatial levels of Table 2 is summarized through the structure diagram of Table 1 . In the 12 spatial structures, all of them are concentrated in the layout of 2 and 3 layers, except the 4-layer structure of case $\bar{\phi}$. First, the sitting room serves as the communal space that receives a guest and shared by family members, it was arranged in the space that enters most easily. But between entrance door and sitting room are set a porch. Porch has decoration in one hand and block the line of sight and protect family privacy in the other hand. Second, the dining room and living room in half space are interconnected. Sitting room and dining-room is connected as communal space for convenience, it also increases communal activity area. Third, as the transition space between public space and private space, people could have a psychological understanding of entering another space after passing corridor.

The structural diagram in table 1 shows the layouts of the balcony are mostly in the position of the master bedroom. The main reasons are that people can contact with nature through the balcony on the one hand, reflecting people's desire to communicate with the outside; On the other hand, the balcony cuts off the line of sight, it is the way of protecting private space. Two or more restrooms are designed in the residence of 120 square metre above, one is designed next to sitting room or corridor, which is the half opened space. Another is in the master bedroom as a private space. There are 3 apartments have the owner's own interest and activity 
space, and this kind of space is also the most hidden part in the 4-layer structure house.

Through the analysis of the internal structure of the residential space, we could discover that the change of level of public and private space is important factor besides the functional demand. The public space such as sitting room, corridor, dining-room should be arrived conveniently and connected to each other. Public space is the place that receives a guest, it needs to show host 's taste. The bedroom and the study are the private spaces, they should provide privacy protection, and offer residents with a spiritual need for rest satisfaction and hobbies.

Table 2. Residential space structure analysis.

\begin{tabular}{|c|c|c|c|c|c|c|}
\hline $\mathrm{C}$ & (1) & (2) & (3) & (4) & (5) & (6) \\
\hline 1 & & & & & & \\
\hline 2 & $\mathrm{R}$ & $\mathrm{RPA}$ & $\mathrm{A}$ & $\mathrm{A}$ & $\mathrm{RPA}$ & $\mathrm{A}$ \\
\hline 3 & $\mathrm{PA}$ & & $\mathrm{RP}$ & $\mathrm{RP}$ & & $\mathrm{RP}$ \\
\hline 4 & & & & & & \\
\hline $\mathrm{C}$ & \multirow{2}{*}{$(7)$} & $(8$ & (9 & (1) & (11) & (12) \\
\hline 1 & & & & & & \\
\hline 2 & & $\mathrm{RA}$ & & $\mathrm{R}$ & & $\mathrm{AR}$ \\
\hline 3 & $\mathrm{~A}$ & $\mathrm{P}$ & $\mathrm{RP}$ & $\mathrm{P}$ & $\mathrm{RPA}$ & $\mathrm{P}$ \\
\hline 4 & $\mathrm{RP}$ & & & & & \\
\hline
\end{tabular}

$(\mathrm{C}=$ case $/ \mathrm{S}=$ structure $)$

\subsection{The cultural-led urban regeneration development of residential space}

Therefore, the traditional way of living is built on the system of etiquette and hierarchy, it paid attention to the expression of cultural artistic conception. Modern residential spaces were designed for saving land, convenience and comfort because of the increasing population, limitations of living space. Based on the analysis of traditional and modern residential spaces, four patterns of culture-led urban regeneration of residential space are summarized.

Firs, regional architectural appearance. The exterior material of the building is the primary factor for people to understand the building. Materials should consider regional characteristics and social ideology. It is not blindly conservative to restore the city to the traditional state, but to re-understand the organization of traditional materials to adapt to the spatial form and aesthetic needs of modern urbans. The combination of tradition and modern may solve the limitations of each sides and to maintain the affinity with people.

Second, Medium public squares are an ideal place to promote the communication of residents. Through public activities in the community square, cultural publicity, residents could participate in the public activities, and enhance communication and understanding to the other community members. It may help residents building cultural identity.

Third, organized public activity area. The layout of the community should be variously. Multi-level open space could be formed according to the use of space. For example, the activity spaces for pedestrians, the landscape near the residential space, and the exercise space for fitness activities. These different spaces enrich the levels of living areas and give residents the psychological identity by meeting different needs.

Fourth, changeable intimacy gradient in space. On building interior layout, the transition change of public space to private space need to be considered. The change of the intimacy level should be gradually changed from the entrance to the most private space, so that people have a different space within the sense of the domain.

\section{Conclusion}

This paper studies the residential space as a concrete reflection of culture. Based on the analysis and summary of the traditional and modern residential space in Henan province, it is found that the cultural features are important for promoting people's emotion such as communication use of regional materials, the construction of public space, the interior space with varying levels. Therefore, four models of residential space regeneration were put forward, which emphasizes the participation of residents and hence improves the design of modern living space. This paper may provide reference to the research on cultural regeneration of residential patterns and promote the sustainable development of urban in the future.

\section{References}

1. Roberts. Peter, Hugh Sykes, Urban Regeneration: A Handbook, Sage Publications Ltd, 1 edition, 7 (2000)

2. Seo. Ick-Jin, An Emperical Analysis on the Type of Cultural Urban Regeneration, Korean Housing and Environment Society, vol. 14-4, 370 (2016)

3. Qi Kang, Urban Stud, Context and characteristics - Cultural characteristics of urban form, 1, 21 (1997)

4. Cheng Yinong, Lifang System and Related Issues Research, Chinese History Research, 3 (2015).

5. Ding Junqing, Chinese residential culture, Tongji University Press, 211(1997).

6. Zheng Dongjun, Huang Hua, A Preliminary Study on the Regional Study of Central Plains Architectural Culture, Chinese and Foreign Architecture 2, 20-23. (1996)

7. B. Hillier, Space is the Machine: A Configurational Theory of Architecture, Cambridge University Press,21-26 (1999). 